\title{
Penggunaan Analisis Korespondensi Sederhana dalam Pemetaan Wilayah Potensi Bencana di Provinsi Sulawesi Tengah
}

\author{
Iis Cendrah Kasih ${ }^{1 *}$, Georgina Maria Tinungki², dan Nasrah Sirajang ${ }^{3}$ \\ 1,2,3 Departemen Statistika, Fakultas MIPA, \\ Universitas Hasanuddin, Makassar, 90245, Indonesia \\ * Corresponding author, email: iiscendrahkasih.91@ gmail.com
}

\begin{abstract}
Disaster cases need to be analyzed considering that when a disaster occurs it will have an extraordinary impact. The statistical method that can be used to study disaster cases is a simple correspondence analysis. This study aims to map areas with the potential for natural disasters in the province of Central Sulawesi. So in the analysis, regions are grouped according to row profile values that are greater than the average. The result of simple correspondence analysis obtained flood disaster has the potential to occur in Banggai, Morowali, Donggala, Buol, Parigi Moutong, Tojo Una-una, Sigi, and North Morowali. While the dominant tornado disaster occurred in Banggai Kepulauan, Banggai, Poso, Toli-toli, Parigi Moutong and Sigi. For regional landslides with potential Banggai Islands, Donggala, Toli-toli, Parigi Moutong, and Sigi. Then Banggai Islands and the City of Palu are the dominant regions for earthquake disasters. The results of the grouping can be the basis of government and community focus in tackling the dominant disasters occurring in their respective regions so as to minimize the impact when natural disasters occur.
\end{abstract}

Keywords: Central Sulawesi, Natural Disaster, Row of Profile, Simple Correspondence Analysis.

\begin{abstract}
Abstrak
Kasus kebencanaan perlu dianalisis mengingat ketika bencana terjadi akan menyebabkan dampak luar biasa. Metode statistika yang dapat digunakan untuk mengkaji kasus kebencanaan ini adalah analisis korespondensi sederhana. Penelitian ini bertujuan memetakan wilayah berpotensi bencana di provinsi Sulawesi Tengah. Sehingga dalam analisisnya beberapa wilayah akan dikelompokkan berdasarkan nilai profil baris yang lebih besar dari rata-ratanya. Adapun hasil analisis korespondensi sederhana yang dilakukan diperoleh bencana banjir berpotensi terjadi di Banggai, Morowali, Donggala, Buol, Parigi Moutong, Tojo Una-una, Sigi, dan Morowali Utara. Sementara bencana puting beliung dominan terjadi di Banggai Kepulauan, Banggai, Poso, Toli-toli, Parigi Moutong dan Sigi. Untuk bencana tanah longsor daerah yang berpotensi Banggai Kepulauan, Donggala, Toli-toli, Parigi Moutong, dan Sigi. Selanjutnya Banggai Kepulauan dan Kota Palu merupakan wilayah dominan terjadi bencana gempa bumi. Hasil pengelompokkan tersebut dapat menjadi landasan fokus pemerintah dan masyarakat dalam menanggulangi bencana yang dominan terjadi di wilayah masing-masing sehingga dapat meminimalisir dampak ketika bencana tersebut terjadi.
\end{abstract}

Kata Kunci: Analisis Korespondensi Sederhana, Bencana Alam, Profil Baris, Sulawesi Tengah.

\section{Pendahuluan}

Bencana alam merupakan peristiwa luar biasa yang dapat menimbulkan penderitaan bagi korbannya. Bencana alam tidak hanya menimbulkan korban jiwa, tetapi juga

Estimasi: Journal of Statistics and Its Application

e-ISSN: 2721-3803, p-ISSN: 2721-379X

http://journal.unhas.ac.id/index.php/ESTIMASI 
menimbulkan dampak psikologis. Mengingat dampak yang luar biasa tersebut, kasus kebencanaan ini perlu dianalisis mengingat ketika bencana terjadi akan menyebabkan dampak yang luar biasa maka diperlukan adanya penanggulangan bencana alam menggunakan prinsip serta cara yang cepat dan tepat [1]. Penanggulangan bencana tidak hanya dilakukan pada saat terjadi bencana tetapi juga pencegahan sebelum bencana terjadi. Pencegahan ini bisa dilakukan mulai dari daerah yang paling rawan bencana alam. Untuk itu diperlukan suatu metode statistika dalam mengidentifikasi daerah rawan terjadi bencana alam. Metode statistika yang dapat digunakan untuk mengkaji kasus kebencanaan ini adalah analisis korespondensi sederhana atau simple correspondence analysis.

Analisis korespondensi sederhana merupakan salah satu teknik analisis multivariat dengan tujuan mempelajari hubungan antara dua variabel kualitatif secara grafik yang digunakan untuk eksplorasi data dari tabel kontingensi dua arah [2]. Analisis korespondensi digunakan apabila semua variabel penelitian bersifat nonmetrik [3]. Data metrik merupakan data berbentuk kuantitatif yang diukur dengan skala interval dan rasio sedangkan data nonmetrik merupakan data berbentuk kualitatif yang diukur dengan skala nominal dan ordinal [4].

Dalam penelitian ini, analisis dilakukan menggunakan data frekuensi kejadian bencana alam yang terjadi pada setiap kabupaten di provinsi Sulawesi Tengah. Pengelompokkan kabupaten rawan bencana alam didasarkan pada nilai profil baris, dan inersia utama, serta kontribusi baris dan kolom yang diperoleh dari hasil analisis. Provinsi Sulawesi Tengah dipilih karena kondisi geologinya berdekatan dengan beberapa sesar aktif yang dapat menimbulkan potensi-potensi besar terhadap bencana. Adapun sesar aktif diantaranya sesar palu koro, sesar sausu di kabupaten Poso, dan beberapa sesar aktif di kepulauan Banggai yakni sesar peleng, sesar naik batui, sesar balantak dan sesar ambelang [5]. Oleh karena itu, penelitian ini bertujuan untuk memetakan wilayah berpotensi bencana alam banjir, puting beliung, tanah longsor, dan gempa bumi pada wilayah provinsi Sulawesi Tengah. Berdasarkan hasil penelitian, pemetaan wilayah potensi bencana sangat diperlukan sebagai upaya mitigasi untuk mengurangi risiko akibat bencana alam.

\section{Metode dan Analisis}

\subsection{Sumber Data}

Penelitian ini menggunakan data sekunder yang diperoleh dari laman resmi Badan Nasional Penanggulangan Bencana (BNPB). Data Informasi Bencana Indonesia (DIBI) merupakan sebuah aplikasi yang menyajikan data bencana alam di Indonesia mulai tahun 1815. Data yang diambil adalah frekuensi kejadian bencana banjir, puting beliung, tanah longsor, dan gempa bumi yang terjadi pada setiap kabupaten di Sulawesi Tengah mulai tahun 1919 sampai dengan tahun 2018. Variabel yang digunakan dalam penelitian ini yaitu kabupaten dan kota di provinsi Sulawesi Tengah dan variabel frekuensi kejadian 
masing-masing bencana alam yaitu bencana alm banjir, puting beliung, tanah longsor dan gempa bumi.

Tabel 1. Frekuensi Kejadian Bencana di Provinsi Sulawesi Tengah

\begin{tabular}{|c|c|c|c|c|c|c|}
\hline No. & Kabupaten dan Kota & Banjir & $\begin{array}{l}\text { Puting } \\
\text { Beliung }\end{array}$ & $\begin{array}{c}\text { Tanah } \\
\text { Longsor }\end{array}$ & $\begin{array}{l}\text { Gempa } \\
\text { Bumi }\end{array}$ & Total \\
\hline 1 & Banggai Kepulauan & 1 & 1 & 1 & 5 & 8 \\
\hline 2 & Banggai & 11 & 1 & 1 & 1 & 14 \\
\hline 3 & Morowali & 18 & 0 & 1 & 2 & 21 \\
\hline 4 & Poso & 18 & 4 & 1 & 3 & 26 \\
\hline 5 & Donggala & 32 & 1 & 5 & 3 & 41 \\
\hline 6 & Toli-toli & 27 & 3 & 3 & 4 & 37 \\
\hline 7 & Buol & 7 & 0 & 0 & 0 & 7 \\
\hline 8 & Parigi Moutong & 48 & 7 & 1 & 2 & 58 \\
\hline 9 & Tojo Una-una & 7 & 0 & 1 & 1 & 9 \\
\hline 10 & Sigi & 13 & 1 & 1 & 0 & 15 \\
\hline 11 & Morowali Utara & 2 & 0 & 0 & 0 & 2 \\
\hline \multirow[t]{2}{*}{12} & Kota Palu & 9 & 0 & 1 & 3 & 13 \\
\hline & Total & 193 & 18 & 16 & 24 & 251 \\
\hline
\end{tabular}

Sumber: Data olah, 2020

Pada Tabel 1 di atas diperoleh informasi bahwa Kabupaten Parigi Moutong merupakan wilayah dengan frekuensi kejadian bencana banjir dan puting beliung yang paling dominan. Untuk bencana tanah longsor paling sering terjadi di wilayah Donggala. Sedangkan bencana gempa bumi paling banyak terjadi di wilayah Banggai Kepulauan. Tabel kontingensi dua arah ini disebut sebagai tabel matriks data yang selanjutnya digunakan untuk analisis korespondensi sederhana.

\subsection{Analisis Korespondensi Sederhana}

Jika $\mathbf{X}$ dan $\mathbf{Y}$ adalah dua variabel yang masing-masing mempunyai sebanyak $a$ dan $b$ kategori, maka dapat dibentuk suatu matriks data pengamatan $\mathbf{P}$ yang berukuran $a \times b$ dengan $p_{i j} \geq 0$ menyatakan frekuensi dari sel $(i, j)$. Dari matriks pengamatan tersebut, untuk mendapatkan sebuah visualisasi baris dan kolom matriks data asli dalam dimensi yang lebih rendah terlebih dahulu dibangun matriks $\mathbf{K}_{(a \times b)}$ sebagai matriks analisis korespondensi yang didefinisikan sebagai berikut:

$$
\mathbf{K}_{(a \times b)}=\left[\begin{array}{cccc}
k_{11} & k_{12} & \cdots & k_{1 b} \\
k_{21} & k_{22} & \cdots & k_{2 b} \\
\vdots & \vdots & \ddots & \vdots \\
k_{a 1} & k_{a 2} & \cdots & k_{a b}
\end{array}\right]=\left[\begin{array}{cccc}
\frac{p_{11}}{p_{. .}} & \frac{p_{12}}{p_{. .}} & \ldots & \frac{p_{1 b}}{p_{. .}} \\
\frac{p_{21}}{p_{. .}} & \frac{p_{22}}{p_{. .}} & \cdots & \frac{p_{2 b}}{p_{. .}} \\
\vdots & \vdots & \ddots & \vdots \\
\frac{p_{a 1}}{p_{. .}} & \frac{p_{a 2}}{p_{. .}} & \cdots & \frac{p_{a b}}{p_{. .}}
\end{array}\right]
$$


keterangan:

$p_{i j}=$ frekuensi pengamatan ke- $i$ baris pada kolom ke- $j$

$p_{. .}=$total jumlah frekuensi dari matriks $\mathbf{P}[6]$.

Bila setiap elemen pada suatu baris dijumlahkan maka diperolah vektor jumlah baris matriks $\mathbf{K}$ yang disebut massa baris yaitu,

$$
\mathbf{r}_{(a \times 1)}^{\mathrm{T}}=\mathbf{K}_{(a \times b)} \mathbf{1}_{(b \times 1)}=\left(\begin{array}{lll}
k_{\mathbf{1}} . & \cdots & k_{\boldsymbol{a}}
\end{array}\right)
$$

dengan cara yang sama, akan didapatkan jumlah setiap kolom dari matriksnya menjadi vektor jumlah kolom dari matriks $\mathbf{K}$ yang disebut massa kolom, yaitu:

$$
\mathbf{c}_{(b \times 1)}=\mathbf{K}_{(b \times a)}^{\mathrm{T}} \mathbf{1}_{(a \times 1)}=\left(\begin{array}{lll}
k_{\cdot 1} & \cdots & k_{\cdot b}
\end{array}\right)^{\mathrm{T}}
$$

Profil adalah proporsi dari setiap baris atau kolom matriks korespondensi yaitu setiap frekuensi pengamatan baris ke- $i$ dan kolom ke- $j$ dibagi dengan jumlah setiap total baris dan kolomnya masing-masing. Kemudian dapat dibentuk matriks $\mathbf{R}$ yang berukuran $a \times$ $b$ sebagai berikut:

$$
\mathbf{R}=\mathbf{D}_{r}^{-1} \mathbf{K}=\left[\begin{array}{cccc}
\frac{k_{11}}{k_{1}} & \frac{k_{12}}{k_{1}} & \cdots & \frac{k_{1 b}}{k_{1}} \\
\frac{k_{21}}{k_{2} \cdot} & \frac{k_{22}}{k_{2}} & \cdots & \frac{k_{2 b}}{k_{2}} \\
\vdots & \vdots & \ddots & \vdots \\
\frac{k_{a 1}}{k_{a}} & \frac{k_{a 2}}{k_{a}} & \cdots & \frac{k_{a b}}{k_{a}}
\end{array}\right]
$$

Matriks $\mathbf{R}$ disebut matriks profil baris (row profiles) dalam ruang berdimensi $b$, dengan jumlah unsur-unsur profil dari baris adalah sama dengan satu. Selanjutnya dilakukan penguraian nilai singular umum atau General Singular Value Decomposition (GSVD) dari matriks residual $\mathbf{K}-\mathbf{r c}^{\mathbf{T}}$.

$$
\mathbf{K}-\mathbf{r c}^{\mathbf{T}}=\mathbf{A} \Sigma \mathbf{B}^{\mathbf{T}}
$$

GSVD dari matriks $\mathbf{K}-\mathbf{r c}^{\mathbf{T}}$ yang hasilnya akan diperoleh matriks-matriks $\mathbf{A} \Sigma \mathbf{B}^{\mathbf{T}}$, dengan $\mathbf{A}$ adalah matriks berukuran $a \times m, \mathbf{B}$ yaitu matriks berukuran $b \times m$, dan $\boldsymbol{\Sigma}$ merupakan matriks diagonal yang unsur-unsurnya merupakan nilai singular dari $\mathbf{K}-$ $\mathbf{r c}^{\mathbf{T}}$. Matriks diagonal $\boldsymbol{\Sigma}$ yang unsur-unsurnya merupakan nilai singular $\mathbf{K}-\mathbf{r c}^{\mathbf{T}}$ apabila dikuadratkan akan menghasilkan nilai eigen atau inersia utama. Sehingga dapat dituliskan sebagai berikut,

$$
\Sigma^{2}=\operatorname{diag}\left(\lambda_{1}^{2}, \cdots, \lambda_{i}^{2}\right)
$$

Besarnya $\lambda_{1}^{2}, \cdots, \lambda_{i}^{2}$ dapat diinterpretasikan sebagai besarnya kontribusi yang diberikan oleh masing-masing dimensi pertama, kedua, dan seterusnya. Dari nilai inersia utama tersebut akan digunakan untuk menentukan jumlah dimensi pada plot analisis korespondensi dengan ketentuan sebagai berikut:

1. Membuang dimensi yang memiliki nilai inersia terkecil. Alasannya adalah bahwa dimensi dengan inersia terkecil mengandung sedikit informasi. Menggunakan prosedur ini dimensi dieliminasi sampai dimensi yang tersisa menjelaskan beberapa persentase yang dipilih sebelumnya dari total keragaman (misalnya $80 \%$ atau lebih). 
2. Beberapa peneliti menggunakan aturan memilih dimensi yang memiliki nilai inersia lebih besar dari satu [7].

Koordinat utama pada plot korespondensi mewakili jarak antar profil baris dari tabel data. Koordinat utama profil baris diperoleh menggunakan rumus sebagai berikut:

$$
\mathbf{F}=\mathbf{D}_{\mathbf{r}}^{-1} \mathbf{A} \Sigma
$$

Selanjutnya, koordinat utama profil kolom dihitung dengan rumus berikut:

$$
\mathbf{G}=\mathbf{D}_{\mathbf{c}}^{-1} \mathbf{B} \Sigma
$$

\section{Hasil dan Diskusi}

Dari data mentah yang kemudian dibentuk matriks data seperti pada Tabel 1, kemudian ditentukan nilai korespondensi untuk setiap selnya menggunakan persamaan (1). Di bawah ini diberikan perhitungan untuk nilai korespondensi baris pertama kolom pertama atau $k_{11}$.

$$
k_{11}=\frac{p_{11}}{p_{. .}}=\frac{1}{251}=0.004
$$

Hasil perhitungan nilai korespondensi untuk baris pertama kolom pertama diperoleh sebesar 0.004, dengan menggunakan persamaan yang sama untuk menentukan nilai korespondensi sel lainnya kemudian didapatkan tabel korespondensi untuk kasus 1

\begin{tabular}{|c|c|c|c|c|c|c|}
\hline No. & Kabupaten dan Kota & Banjir & $\begin{array}{c}\text { Puting } \\
\text { Beliung }\end{array}$ & $\begin{array}{c}\text { Tanah } \\
\text { Longsor }\end{array}$ & $\begin{array}{c}\text { Gempa } \\
\text { Bumi }\end{array}$ & $\begin{array}{c}\text { Massa } \\
\text { Baris }\end{array}$ \\
\hline 1 & Banggai Kepulauan & 0.004 & 0.004 & 0.004 & 0.020 & 0.032 \\
\hline 2 & Banggai & 0.044 & 0.004 & 0.004 & 0.004 & 0.056 \\
\hline 3 & Morowali & 0.072 & 0.000 & 0.004 & 0.008 & 0.084 \\
\hline 4 & Poso & 0.072 & 0.016 & 0.004 & 0.012 & 0.104 \\
\hline 5 & Donggala & 0.127 & 0.004 & 0.020 & 0.012 & 0.163 \\
\hline 6 & Toli-toli & 0.108 & 0.012 & 0.012 & 0.016 & 0.147 \\
\hline 7 & Buol & 0.028 & 0.000 & 0.000 & 0.000 & 0.028 \\
\hline 8 & Parigi Moutong & 0.191 & 0.028 & 0.004 & 0.008 & 0.231 \\
\hline 9 & Tojo Una-una & 0.028 & 0.000 & 0.004 & 0.004 & 0.036 \\
\hline 10 & Sigi & 0.052 & 0.004 & 0.004 & 0.000 & 0.060 \\
\hline 11 & Morowali Utara & 0.008 & 0.000 & 0.000 & 0.000 & 0.008 \\
\hline 12 & Kota Palu & 0.036 & 0.000 & 0.004 & 0.012 & 0.052 \\
\hline & Massa Kolom & 0.769 & 0.072 & 0.064 & 0.096 & 1 \\
\hline
\end{tabular}
sebagai berikut:

Tabel 2. Nilai Korespondensi Provinsi dengan Frekuensi Bencana Alam

Sumber: Data olah, 2020 
Selanjutnya menghitung nilai korespondensi untuk semua sel dapat diperoleh nilai massa baris dan massa kolom yang disimbolkan masing-masing $r$ dan c. Berdasarkan persamaan (2) dan (3) bila setiap elemen pada suatu baris dan kolom dijumlahkan maka diperoleh vektor jumlah baris dan kolom. Adapun vektor massa baris dan kolom dapat dilihat pada Tabel 2. Selanjutnya ditentukan nilai profil baris untuk provinsi Sulawesi Tengah dengan persamaan (4) yang nilainya dapat dilihat pada Tabel 3.

Tabel 3. Profil Baris Provinsi Sulawesi Tengah dan Frekuensi Bencana

\begin{tabular}{|c|c|c|c|c|c|c|}
\hline No. & Kabupaten dan Kota & Banjir & $\begin{array}{c}\text { Puting } \\
\text { Beliung }\end{array}$ & $\begin{array}{c}\text { Tanah } \\
\text { Longsor }\end{array}$ & $\begin{array}{l}\text { Gempa } \\
\text { Bumi }\end{array}$ & Total \\
\hline 1 & Banggai Kepulauan & 0.125 & 0.125 & 0.125 & 0.625 & 1 \\
\hline 2 & Banggai & 0.786 & 0.071 & 0.071 & 0.071 & 1 \\
\hline 3 & Morowali & 0.857 & 0.000 & 0.048 & 0.095 & 1 \\
\hline 4 & Poso & 0.692 & 0.154 & 0.038 & 0.115 & 1 \\
\hline 5 & Donggala & 0.780 & 0.024 & 0.122 & 0.073 & 1 \\
\hline 6 & Toli-toli & 0.730 & 0.081 & 0.081 & 0.108 & 1 \\
\hline 7 & Buol & 1.000 & 0.000 & 0.000 & 0.000 & 1 \\
\hline 8 & Parigi Moutong & 0.828 & 0.121 & 0.017 & 0.034 & 1 \\
\hline 9 & Tojo Una-una & 0.778 & 0.000 & 0.111 & 0.111 & 1 \\
\hline 10 & Sigi & 0.867 & 0.067 & 0.067 & 0.000 & 1 \\
\hline 11 & Morowali Utara & 1.000 & 0.000 & 0.000 & 0.000 & 1 \\
\hline \multirow[t]{2}{*}{12} & Kota Palu & 0.692 & 0.000 & 0.077 & 0.231 & 1 \\
\hline & Mean & 0.761 & 0.054 & 0.063 & 0.122 & 1 \\
\hline
\end{tabular}

Sumber: Data olah, 2020

Berdasarkan nilai profil baris dari Tabel 3 diperoleh informasi bahwa Kabupaten Banggai, Morowali, Donggala, Buol, Parigi Moutong, Tojo Una-una, Sigi, dan Morowali Utara terletak pada posisi yang berdekatan dengan bencana alam banjir dibuktikan dengan nilai profil baris masing-masing kabupaten yang lebih besar dari nilai rata-rata (mean) yaitu 0.761. Sedangkan bencana puting beliung terletak paling dekat dengan kabupaten Banggai Kepulauan, Banggai, Poso, Toli-toli, Parigi Moutong dan Sigi dengan nilai profil masing-masing yang lebih besar dari nilai rata-rata (mean) yaitu 0.054. Kabupaten Banggai Kepulauan, Donggala, Toli-toli, Parigi Moutong, dan Sigi terletak berdekatan dengan bencana alam tanah longsor dibuktikan dengan nilai profil baris masing-masing kabupaten yang lebih besar dari nilai rata-rata (mean) yaitu 0.063. Serta bencana alam gempa bumi terletak berdekatan dengan Banggai Kepulauan dan Kota Palu dengan masing-masing nilai profil baris 0.625 dan 0.231 yang lebih besar dari nilai rata-rata (mean) yaitu 0.122 .

Langkah selanjutnya adalah melakukan penguraian nilai singular umum pada matriks $\mathbf{K}-\mathbf{r c}^{\mathbf{T}}$ berdasarkan persamaan (2) yang akan menghasilkan matriks $\mathbf{A} \Sigma \mathbf{B}^{\mathbf{T}}$. Dari hasil penguraian nilai singular tersebut diperoleh matriks $\Sigma$ yang nilai-nilai diagonalnya 
berisikan nilai singular. Berdasarkan persamaan (2) diperoleh nilai eigen atau inersia utama dengan cara mengkuadratkan nilai-nilai singular dari matriks $\Sigma$. Nilai eigen atau inersia utama tiap barisnya menyatakan keragaman yang dijelaskan masing-masing dimensi dan biasanya disusun terurut mulai dari nilai terbesar hingga nilai terkecil. Adapun nilai eigen atau inersia utama dari matriks $\mathbf{K}-\mathbf{r c}^{\mathbf{T}}$ disajikan pada Tabel 4 sebagai berikut:

Tabel 4. Persentase Kumulatif Nilai Eigen

\begin{tabular}{cccc}
\hline & Nilai Eigen & Persentase Variansi & Persentase Kumulatif Variansi \\
\hline Dim. 1 & 0.150 & 71.36 & 71.36 \\
Dim. 2 & 0.048 & 22.80 & 94.16 \\
Dim. 3 & 0.012 & 5.84 & 100.00 \\
\hline
\end{tabular}

Sumber: Data olah, 2020

Pada Tabel 4 diperoleh nilai persentase kumulatif untuk dimensi 1 dan dimensi 2 sebesar $94.16 \%$. Karena persentase kumulatif dari dimensi 1 dan 2 sudah menjelaskan variansi lebih dari $80 \%$ dari solusi maka jumlah sumbu yang digunakan pada plotting sebanyak dua dimensi.

Selanjutnya ditentukan koordinat utama baris dan kolom menggunakan persamaan (2.7) dan (2.8). Nilai matriks kontribusi baris A digunakan untuk menentukan koordinat utama baris sedangkan nilai matriks kontribusi kolom B digunakan untuk menentukan koordinat utama kolom.

Tabel 5. Koordinat Utama Baris

\begin{tabular}{cccc}
\hline No. & Kabupaten/Kota & Dim.1 & Dim.2 \\
\hline 1 & Banggai Kepulauan & 1.880876 & -0.043960 \\
2 & Banggai & -0.072213 & 0.043243 \\
3 & Morowali & -0.061563 & -0.185829 \\
4 & Poso & 0.083250 & 0.043741 \\
5 & Donggala & -0.033060 & 0.137885 \\
6 & Toli-toli & 0.067969 & 0.070117 \\
7 & Buol & -0.438088 & -0.291240 \\
8 & Parigi Moutong & -0.232653 & -0.036677 \\
9 & Tojo Una-una & 0.067429 & 0.029846 \\
10 & Sigi & -0.320430 & 0.066020 \\
11 & Morowali Utara & -0.438088 & -0.291240 \\
12 & Kota Palu & 0.428403 & -0.172970 \\
\hline
\end{tabular}

Sumber: Data olah, 2020

Pada Tabel 5 menjelaskan letak titik atau koordinat dari tiap kabupaten. Dimensi satu menunjukkan sumbu x dan dimensi dua menunjukkan sumbu y. 
Tabel 6. Koordinat utama kolom

\begin{tabular}{ccc}
\hline Bencana Alam & Dim. 1 & Dim. 2 \\
\hline Banjir & -0.169747 & -0.032272 \\
Puting Beliung & 0.052119 & 0.166410 \\
Tanah Longsor & 0.292231 & 0.362866 \\
Gempa Bumi & 1.131138 & -0.107195 \\
\hline
\end{tabular}

Sumber: Data olah, 2020

Pada Tabel 6 menjelaskan letak titik atau koordinat dari tiap bencana alam. Dimensi satu menunjukkan sumbu $\mathrm{x}$ dan dimensi dua menunjukkan sumbu y. Di bawah ini ditampilkan plot korespondensi berdimensi rendah (dua) menggunakan koordinat utama baris dan kolom sebelumnya.

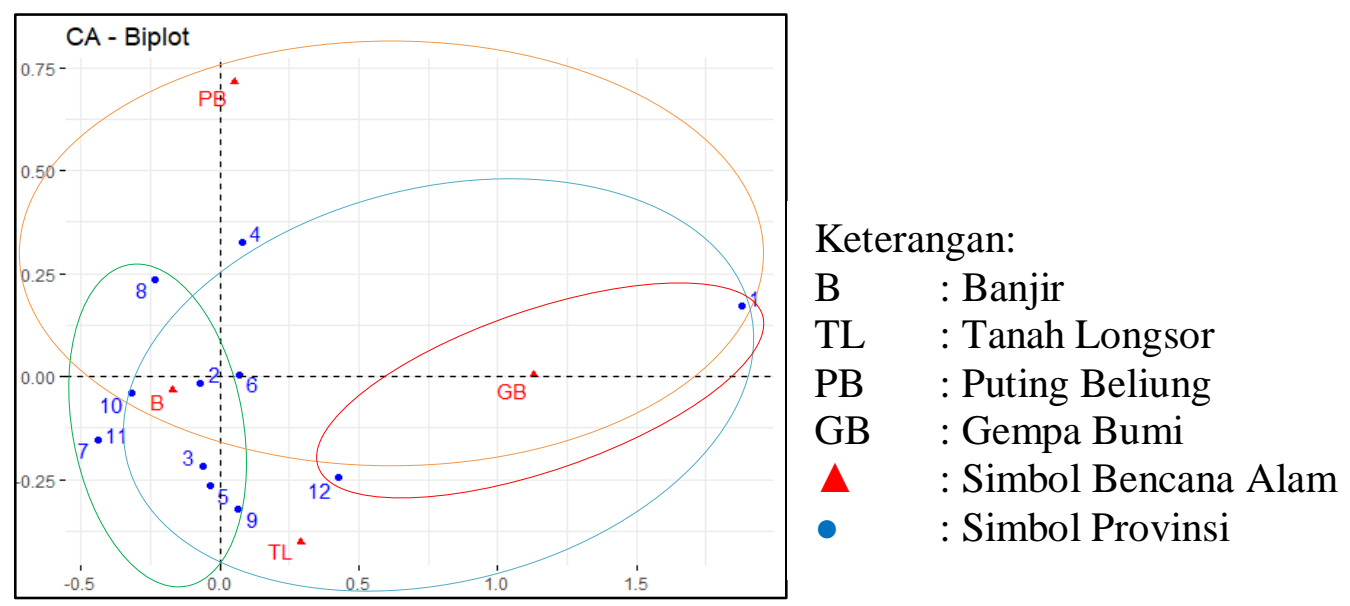

Gambar 1. Pengelompokkan Wilayah dan Potensi Bencana Alamnya di Sulawesi Tengah dengan menggunakan program $\mathrm{R}$ versi 3.5.3

Pada Gambar 1 dapat diinterpretasi berdasarkan nilai profil barisnya. Kelompok pertama ditunjukkan oleh Kabupaten Banggai, Morowali, Donggala, Buol, Parigi Moutong, Tojo Una-una, Sigi, dan Morowali Utara yang terletak berdekatan dengan bencana alam banjir, ini menginformasikan bahwa perlunya dilakukan penanggulangan bencana banjir oleh seluruh warga di wilayah tersebut. Sedangkan kelompok kedua yaitu bencana puting beliung yang terletak paling dekat dengan Kabupaten Banggai Kepulauan, Banggai, Poso, Toli-toli, Parigi Moutong dan Sigi, yang artinya pemerintah maupun masyarakat di wilayah tersebut harus mengadakan antisipasi sebelum bencana terjadi mengingat bencana tersebut merupakan bencana dengan frekunsi kejadian terbanyak. Kelompok ketiga ditunjukkan oleh Kabupaten Banggai Kepulauan, Donggala, Toli-toli, Parigi Moutong, dan Sigi, hal ini menunjukkan bahwa penanggulangan bencana tanah longsor harus dilakukan di kelima kabupaten tersebut. Serta kelompok keempat yaitu bencana alam gempa bumi yang terletak berdekatan dengan Kabupaten Banggai 
Kepulauan dan Kota Palu mengindikasikan bahwa bencana tersebut adalah kejadian dengan frekuensi terbanyak di Sulawesi Tengah sehingga perlu diadakan sosialisasi cara menghadapi gempa bumi oleh pemerintah di wilayah tersebut agar dapat meminimalisir korban jiwa dan kerugian ketika bencana gempa bumi terjadi.

\section{Kesimpulan}

Dari hasil analisis korespondensi sederhana yang dilakukan untuk memetakan wilayah kabupaten dan kota di provinsi Sulawesi Tengah diperoleh pengelompokan wilayah dengan masing-masing potensi bencana berdasarkan nilai profil baris yang lebih besar dari rata-ratanya. Adapun bencana banjir berpotensi terjadi di Kabupaten Banggai, Morowali, Donggala, Buol, Parigi Moutong, Tojo Una-una, Sigi, dan Morowali Utara berdasarkan nilai profil baris masing-masing kabupaten yang lebih besar dari nilai ratarata 0.761 . Sementara bencana puting beliung dominan terjadi di kabupaten dengan nilai profil baris lebih besar dari nilai rata-rata 0.054 yaitu Kabupaten Banggai Kepulauan, Banggai, Poso, Toli-toli, Parigi Moutong dan Sigi. Untuk bencana tanah longsor daerah yang berpotensi Kabupaten Banggai Kepulauan, Donggala, Toli-toli, Parigi Moutong, dan Sigi dengan masing-masing nilai profil barisnya lebih besar dari nilai rata-rata 0.063. Kemudian Kabupaten Banggai Kepulauan dan Kota Palu merupakan wilayah yang dominan terjadi bencana alam gempa bumi dengan nilai profil baris yang lebih besar dari nilai rata-rata 0.122 . Hasil pengelompokkan tersebut dapat menjadi landasan fokus pemerintah dan masyarakat dalam melaksanakan penanggulangan bencana yang dominan terjadi di wilayah masing-masing sehingga pencegahan yang dilakukan dapat meminimalisir dampak ketika bencana alam tersebut terjadi.

\section{Daftar Pustaka}

[1] Setiawan, I. 2009. "Pemanfaatan Sistem Informasi Geografis untuk Zonasi Tingkat Kerawanan Bencana Letusan Gunung Api Tangkubanparahu". Skripsi. Buana Nusantara. Bandung.

[2] Mattjik, Sumertajaya, A. A., \& Made, I. 2011. Sidik Peubah Ganda dengan Menggunakan SAS. Bogor: Institut Pertanian Bogor.

[3] Ghozali, I. 2011. Apilkasi Analisis Multivariat dengan Program IBM SPSS 19. Semarang: Universitas Diponegoro.

[4] David, W. \& Djamaris, A. 2018. Metode Statistik untuk Ilmu dan Teknologi Pangan. Jakarta Selatan: Universitas Bakrie.

[5] Pakpahan, S. \& Ngadmanto, D. 2015. Analisis Kegempaan di Zona Sesar Palu Koro, Sulawesi Tengah. Journal of Environment and Geological Hazards. 6. 253264.

[6] Greenacre, M. J. 1984. Theory and Applications of Correspondence Analysis. London: Academic Press. 
Penggunaan Analisis Korespondensi Sederhana ...

Iis Cendrah Kasih, Georgina Maria Tinungki, Nasrah Sirajang

[7] Fekedulegn, B. D., Colbert, J. J., Hicks, R. R. Jr., \& Schuckers, M. E. 2002. Coping with Multicollinearity: An Example on Application of Principal Components Regression in Dendroecology. United States Department of Agriculture: Newton Square. 